\title{
Potential of Posthumanist onto-epistemology for the study of International Relations
}

\section{Penttinen, Elina}

Routledge

2018

Penttinen , E 2018 , Potential of Posthumanist onto-epistemology for the study of International Relations . in E Cudworth , S Hobden \& E Kavalski (eds), Posthuman

Dialogues in International Relations . Routledge , Abingdon ; New York, NY , pp. 72-88 . https://doi.org/10.4324/978

http://hdl.handle.net/10138/309424

https://doi.org/10.4324/9781315613475-5

unspecified

acceptedVersion

Downloaded from Helda, University of Helsinki institutional repository.

This is an electronic reprint of the original article.

This reprint may differ from the original in pagination and typographic detail.

Please cite the original version. 
Penttinen, Elina (2017) Potential of Posthumanist onto-epistemology for the study of International Relations, in Stephen Hobden (ed) Posthuman Dialogues in IR. Ashgate Research Companion series. Ashgate: UK. pp.72-88

\section{Elina Penttinen}

Potential of Posthumanist onto-epistemology for the study of International

\section{Relations}

The world is given to me only once, not one existing and one perceived. Subject and object are only one. The barrier between them cannot be said to have broken down as a result of recent experience in physical sciences, for this barrier does not exist.

Erwin Schrödinger ${ }^{1}$

So, in a deep enough view, we in our act of observation are like that we observe: relatively constant patterns abstracted from the universal field movement, and thus merging ultimately with all other patterns that can be abstracted from this movement.

David Bohm (1996: p.94 italics original)

This chapter discusses the potential of a non-fragmented and non-dualist ontoepistemology for the study of International Relations (IR) based on philosophical implications of second wave quantum mechanics. I build on physicist philosopher 
David Bohm's conceptualization of Implicate order and Karen Barad's posthumanist theorizing on intra-activity of hunans and non-humans based on Niels Bohr's philosophy-physics. Both these approaches position the human in non-dualist postclassical and posthumanist terms as part of the reconfiguration of the world in its continuous becoming (Barad) or in the flow of the stream of reality (Bohm). Thus, they both critique the anthropocentric conceptualization of knowledge as something which is assigned to human and static notions of matter, materiality, knowing and being. They highlight, albeit in different ways, the limitations of anthropocentric conceptualization of knowing, being and how these lead to confusion in light of recent scientific developments in quantum mechanics. They both place emphasis on the responsibility of human as part of the process as being ontologically entangled with the whole of reality. Moreover, they both in different ways recognize the agentiality and aliveness of matter and thus challenge the settled distinctions between nature culture, mind-body, self and other which are often implicit our inquiry also in the field of International Relations. The non-dualist and non-fragmented onto-epistemology is founded on the critique of dominating paradigms and scientific dogmas, which render human in a position of superiority in relation to knowing and being in the world.

My objective in this chapter is to open up discussion of how rethinking and reevaluating unquestioned assumptions or scientific paradigm can enhance the practice of IR scholarship in contemporary world marked by crisis, instability, insecurity and growing global inequalities. Global financial crisis, war on terror, climate change and the increasing flow of refugees demand us to recognize the interconnectedness of politics, policies, society, nature and culture. In this regard I see the potential of 
posthumanist IR (Cudrow and Hobden 2011) as necessary in order to keep up to speed with continuously changing world and create scholarship which is pro-active instead of reactive to world-events. Non-fragmented onto-epistemology provides a way to move beyond the limitations of IR which I see relying in the ontology of separation and metaphysical individualism.

My aim is not to present a new world-view based on non-fragmentation, or establish a new paradigm, but instead open up discussion and our imagination to new ways of approaching what knowing and being is. This means critically examining the unquestioned assumptions about the nature of nature and nature of matter which guide our inquiry across positivist and post-structuralist approaches. Bohm (2007: 80) emphasizes that when we are not aware of our unquestioned assumptions it is the assumptions that are doing the observation instead of the observer. In this way, the observer is the observed in a very intimate and personal way. The scientific method in itself is a means to open up to new facts and new information. Scientific inquiry does not have to operate for the purpose of supporting established facts or paradigms which are indeed ideological constructs, such as faith in science (Stengers 2010) or anthropocentric metaphors seen as true representations of physical realm, such as 'laws of nature'.

I approach this question from feminist poststructuralist methods for globalized worldeconomy and complex security environment. I have argued elsewhere (Penttinen 2013) that much of critical theorizing in IR is based on what I call the ontology of suffering. This means that in IR our focus is on the study of injustice, inequality and exploitation 
that manifests in contemporary world from the point of view of scarcity, competition and lack. Thus, critical theorists are not that far from the world-view of realism which sees life as 'nasty, brutish and short' (Walker 2010). The shared antihumanist conceptualization sees human beings as vulnerable, fragile and at the mercy of outside conditions (Csikszentmihalyi 2011) and this idea is hardly contested in post-structuralist approaches. Even though these challenge positivist world-view the implicit antihumanism remains. An example of this is the common sense assumption that war is a source of human suffering and therefore it is difficult to pay attention how war generates social orders (Barkawi and Brighton 2011). Chan (2011) argues that in IR we are drawn to spectacular violence and limit from our analysis how people live their everyday lives in the midst of violent conflicts. These examples show how our assumptions guide our inquiry. However, the trouble is that when the ontology of suffering informs the inquiry it is easy to become seduced by the idea that suffering, inequality or scarcity is all there is. In order to hold onto ontology of suffering, or support the dominating paradigm, we must dismiss evidence which shows otherwise For example recognizing how people live and create their lives in the midst of constricting conditions challenges common sense assumption on how much outside conditions and dominating discourses determine individual experiences and possibilities. Moreover, in our focus on social and political worlds in humanist terms, we reiterate the mechanistic-deterministic conceptualization of nature which sees nature as passive, mute and immutable (Barad, 2007: p.133).

Posthumanist theorizing challenges us to rethink the nature-culture, mind-body relationships and re-examine how seeing nature in mechanistic terms, as passive, mute 
and without agency is based on a world-view which is being challenged in light of recent scientific research in the fields of physics, neurosciences and neurobiology. For example, recent research on neuroethics (Churchland 2012) shows the capacity of rats for altruistic behavior. Neurobiological study of mirror neurons in the brain show the interconnectedness of functions in practice and how we are able to feel each other's feelings (Hari 2015, Isen 2009, Damasio 1999) Research such as these challenges the metaphysical individualism, understanding that we are ontologically separate subject with individual experiences. Or that mind is situated in the individual brains. Rather recent research points to inter-being (Varela 1999) or subjectivity as in-between-selves (Kwee 2012).

Recent scientific developments should at least spark a little bit curiosity towards reevaluating the ontological dualism and metaphysical individualism (Coole and Frost 2010, Barad 2003). Even though the field of IR is fragmented in various subfields along the positivist-postpositivist/post-structuralist continuum (see also Sylvester 2009), my argument is that these different subfields have in common the ontological distinction between nature-culture, mind- body, self- other, human and non-human.

Here I follow Bennett (2010) and Coole and Frost (2010) in highlighting how the poststructuralist and antifoundational approaches have enforced the separation between social and natural worlds, meaning that the social world is seen as ontologically different from the natural world. Bennett (2010) argues that the linguistic turn in social science has turned our attention to language, discursive communities, narratives and semiotics as a sphere in which we see the formation of subjectivity and 
agency in the social world. These approaches have been formed through juxtaposition against classical notions of physics, but do not challenge whether the classical view of physics is applicable to the natural world. Coole and Frost contend that (2010) that the established skepticism against naïve realism and representationalism as well as toward Marxist and critical realism has influenced the overall move toward more abstraction, dismissing matter and materiality as irrelevant and reinforcing the nature-culture distinction. This move towards more abstraction and separation between social and natural worlds is problematic as it reiterates a Newtonian view of nature which recent development in science have challenged. Thus, the ontological distinctions between nature and culture remain intact. As a potential alternative I suggest a non-fragmented onto-epistemology for the study of IR.

What would it mean in the context of IR to shift away from a worldview of ontological separation and metaphysical individualism and engage in an inquiry on the international from the perspective of ontological entanglement and unpredictable aliveness of matter? What kind of things would 'we' be looking at and how would we do the 'looking'? Would it be the world instead looking and communicating through us?

I will continue this discussion first by summarizing the scale and scope of technological developments based on second wave quantum mechanics. I will then move on to diffractive reading Barad's and Bohm's philosophy-physics and discuss how the non-fragmented and non-dualist understanding of knowing and being can open up IR as a discipline to account for more aliveness and more responsibility in terms of how we perceive and participate in the world. My intention is not to suggest a return to 
the paradigm of natural sciences as the guiding principle for social sciences and thus reproduce the ideology behind behavioralist and overall positivist approaches within international relations research, but to open up discussion on how our unquestioned assumptions limit us from recognizing the pluripotency and aliveness of matter which second wave quantum mechanics points towards. It is for this reason that I first turn to the relevance of technological developments as to how they tie in with the concerns of IR.

\section{WHY SHOULD WE CARE ABOUT QUANTUM MECHANICS IN IR?}

In the midst of everyday reality, (the micro level in IR) it is easy to forget and also take for granted the numerous ways in which quantum mechanics leads to a different understanding of the physical reality from that which we perceive with our eyes. The main concerns of International Relations theory are somewhere in between the cosmos and the subatomic worlds. Therefore, it is easy to ignore how the new discoveries of the second quantum mechanics affect the foundations of social sciences philosophically. This would be so even if we were to recognize how the emergence of new technologies, nanotechnology, bioengineering, and biomimesis fall right in the middle of IR concerns, as their impact is substantial in respect of military strategy, global political economy and ethics.

Quantum mechanics is present in our everyday lives in many mundane ways that we take for granted. It is said that one-third of the US economy depends on it, and many technologies such as semiconductors, lasers PET and MRI scans contribute to and 
facilitate everyday life (Rosenblum and Kuttner, 2006). Recent scientific developments should also interest IR more generally, as it is also funded by the Pentagon and is of great interest to NASA (Barad, 2007) and thus comes under the umbrella of war and power politics. For example, the pentagon has funded research on the possibility to bend light around an object, which would enable to create the illusion of invisibility. The advantage of invisible helicopters or invisible soldiers would change fundamentally strategies and fighting in the context of war. Research and design for military technologies influence the application of technologies for civilian use and further into consumer society. For example the military robots designed in the US for the purpose of doing the dull and dirty work in warfare, peculiarly constructed in the form of animals imitating their posture and movements such as military dogs (BigDog), or a headless mule, reiterate and reinvent human and non-human, and non-human animal and machine relations. Welfare robotics mainstream these ideas into the health and care sector with the design of gendered 'human like' robots in Japan by the company ARPANET. Last bioengineering products for both military and civilian purposes such as Biosteel®, a trademark for high strength material extracted from the milk of transgenic goats that is used for military purposes such as fabrication of bullet proof wests and sutures, transform power relations in context of war and simultaneously open new possibilities for better care of surgical patients.

Recognizing quantum mechanics as a metaphor of non-linear emergence characteristic of contemporary international politics has already been done by Der Derian (2009, 2013) in which he argues how circulation of images and information generates consequences in non-linear terms. The analogy of the quantum enables to recognize the 
non-local emergence and entanglement of world events which defy linear logic of push and pull factors and challenges the idea of matter having intrinsic properties. Der Derian takes the analogy of the quantum as illustrative how war and conflict is generated contemporary world. Yet my objective here is not to analyze the implications of cyberwarfare in the context of war strategy, or the influence of quantum mechanics on consumer possibilities in the future or use quantum mechanics as an analogy of world politics, but to focus more on the philosophical implications of quantum theory because these are counterintuitive to our commonsense view of the natural world.

Cudrow and Hobson (2011) conceptualize the relevance of the concept of environment for the study of IR by emphasizing that including the environment as 'issue' is not enough as there really is no human beings or societies do not function separately from the environment which gives us life. Similarly, the implications of quantum mechanics in the field of IR are more than including the technological developments as an 'issue' as these challenge the implicit classical notions of physics which inform IR theory. Therefore we need a posthuman IR which is able to move beyond anthropocentric notions and ontology of separation between natural and cultural world. Morever, as Bousquet argues (2015) it is necessary for posthumanist IR to recognize the complex relationship of humans with both biosphere and technosphere in the process of coconstitution of reality. This echoes in the way in which Ferrando (2015) challenges the way in which we see technology as the new other, a place assigned formerly to women, the orient and the exotic, and calls for recognition of the complex relationships between humans and technologies in the process of creating posthumanist ontology. 
Thus, the implications of quantum mechanics for IR is the challenge to rethink the unquestioned assumptions of classical physics which guide our analysis to look for linear causes and effects, push and pull factors, or identity politics which sees identity, subjectivity and agency as a property of a person. The evidence based on quantum theory points to non-locality, uncertainty, superposition demonstrated by the wave function, and the entanglement of observer, measuring device and object of observation in the process of measurement.

Quantum theory has for example 'an atom being a spread out wave or a concentrated particle' (Rosenblum and Kuttner, 2006: p.126) and is not therefore predetermined. Instead it is context specific. This is represented for example by the which-path or which-slit experiments, which have shown how an object can act both as a particle and as a wave depending on the experiment (Hiley 2000, Barad, 2007: 98-106). The evidence of superpositions shows that one object could be in two different states at once, goes against the philosophy of classical physics. Bohm argues that at quantum level, the atomistic theory leads to confusion as it is based on the assumption of indivisible particles as 'building blocks' of reality (Bohm 2005, p. 13). Similarly, the evidence of non-locality is counter to the classical view of matter, showing that once two particles have been in contact, they change simultaneously in the same way when they are irrigated, even after they are separated and distanced from each other. ${ }^{2}$ Similarly, the recent example of long-distance quantum teleportation challenges how we understand the nature of matter. The innovative technologies, such as quantum computing, quantum cryptography apply the theory of entanglement successfully (Barad, 2007: p.386), showing the limitations of classical physics in terms of producing 
innovations and certainly raising ethical questions in respect of nature and human involvement with it.

Quantum mechanics points towards a relational aspect of bodies, societies, nature, environment, subatomic worlds and the cosmos. It challenges us to think how matter comes to matter, and the nature of nature, as quantum theory opens a new conceptualization of matter.

The evidence of quantum mechanics have attracted many creative explanations. These range from the many worlds theory (see e.g. Saunders, Barrett, Kent and Wallace 2010), string theory and M-theory as developed by Kaku (2000), to implicate order as developed by David Bohm (2008), as well as attributing the collapse of the wave function to the human mind or consciousness (Hameroff 2007, Rosenblum and Kuttner, 2006). This list is not exhaustive. So far, there is no consensus on what quantum mechanics means in philosophical terms about the nature of nature and nature of being and knowing (Barad, 2007; Rosenblum and Kuttner, 2006).

One reason why philosophical questions have been avoided is that the common interpretation of quantum theory is that quantum formalism applies only to the micro world and the macro world obeys classical physics. ${ }^{3}$ However, the wave function has been tested with larger and larger particles, up to and including medium-sized proteins, ${ }^{4}$ showing that even these can act both as waves and as particles. This shows that the understanding of what is the boundary between the micro and macro worlds is shifting. The second reason for avoiding the philosophical implications is due to cognitive 
repression (Zeilinger 1996). Because Newtonian world-view has become the common sense, evidence that goes against this has to be denied, ridiculed or dismissed. Bohm argues, that one of the reasons is that because the wave-function offers a static way to understand quantum mechanics and the ontology of classical physics does not need to be challenged.

In this section I have discussed the scale of the technological developments based on second wave quantum mechanics as something which is relevant in the context of IR, as these shape and are embedded in global politics. Quantum mechanics matter in terms of contributing to new innovation and technological developments constituting a growing share of global political economy. Technological developments reconfigure human and non-human and human machine. Therefore, I follow Bousquet (2015) in emphasizing that IR as a field has a lot to gain by recognizing the interconnected, entanglement of human as part of the biosphere and technosphere. Including technology as an issue in global politics would be a mistake, for this view is based on anthropocentric conceptualization of the place and role of humans in the world. What is relevant here is to pay attention how goundbreaking developments based on second wave quantum mechanics highlight how the natural-cultural, human non-human relations are continually reconfigured and ontologically relational and entangled. Thus, in line with physicist-philosophers Bohm and Barad, I want to emphasize that also the philosophical implications of second wave quantum mechanics need to be considered. These implications are also relevant for the field of International Relations as the ontological assumptions based on classical physics also informs IR theorizing. Posthuman IR is a way to challenge these unquestioned assumptions, which limit our understanding of the 
complex relations of human and non-human relations. Next, I will discuss how Bohm and Barad discuss the philosophical implications of quantum theory. I will in end this chapter with discussion on what implications this onto-epistemology implies for the responsibility of the researcher in the context of IR.

POSTHUMANIST ONTO-EPISTEMOLOGY: Diffractive reading of Bohm and Barad

In this section, I focus on the philosophy-physics of Bohm and Barad as they both explicitly consider the posthumanist onto-epistemology based on quantum mechanics in terms of ethics and responsibility. This, I believe can also enhance the research practice in the field of International Relations.

Both Barad and Bohm see the importance in re-evaluating common sense perceptions of the world, anthropocentric conceptualization of knowing and dualistic understanding between mind and matter. Thus, they both want to challenge not only the common sense perception of the way nature 'works' based on quantum theory, but extend this challenge to the positon, or role of the observer in the process and ultimately what 'knowing' is. According to Hiley (2000), for Bohm it was not logical to think of the mind in classical terms and at the same time conceptualize matter in post-classical terms. Thus, re-evaluating how quantum theory challenges the role and position of the observer in the process of knowledge is also necessary.

What Barad and Bohm share is the critique of the anthropocentric, Cartesian principle of knowing. They both challenge the idea of the thinking human as the subject 
of knowledge and mind-body dualism. For Bohm thinking, theories and instruments and spacetime are projections which emerge out of the ongoing flow or movement emerging from the enfolded order. Bohm explains that both relativity and quantum theory points towards the understanding that 'both observer and observed are merging and interprenetating aspects of one reality, which is indivisible and unanalysable (Bohm 2005, p.12)”.

Both Bohm and Barad, albeit in different ways, speculate what the indivisibility of the observing instrument and the observed entails for the conceptualization of the role of the observer in the process. Bohm combines the conceptualization of unified field from theory and quantum mechanics and sees both the thinking mind, the instrument and the observed as indivisible and indeterminate projections of an enfolded or implicate order. Bohm (2005) argues that both theory of relativity and quantum theory point to an understanding of the physical reality as a continuous movement such as a stream. The stream represents the whole of movement, in which the vortices and wave patterns can be seen to represent the localized regions. Then 'what is' is a form of continuous movement of the whole, including the human being as part of it. Studying the vortices or wave patterns separately from the whole does not in this framework make any sense in this framework. This, according to Bohm, relates to Einstein's conception of the field, which is an undivided and unbroken whole, but Bohm takes the notion of the field even further. He shows that the observer, or the one who measures, cannot be regarded as something that exists separately from the field itself. The order does not refer to order of the physical world in classical sense, but at a deeper level as an ontological harmony or coherence underlying the movement and flow of the world. 
Bohm emphasizes that the notion of analyzing the whole of the universe as basic 'building blocks' is thus utterly irrelevant (Bohm, 1996, p.93). The Aristotelian logic in this context is turned around to conceptualize "what is" as the whole of movement. In this framework, thought and non-thought are not mutually exclusive, but instead mutually constitutive. The Cartesian notion, which prioritizes thinking as a sign of existence is turned around to recognize how existence gives rise to thinking. Thinking in this context is a projection of the enfolded order, and not a sign of privilege of humans over the natural world.

Barad builds on Niels Bohrs' ideas conceptualization of observer, observing instrument and the observed as constituting the whole of the phenomenon and follows Bohr's understanding that all three, observer, observing instrument and the observer should be understood in post-classical terms. Thus, for Barad knowing is a matter of communication of these three parts which become differentially intellibigle to each other at the moment of the measurement. This approach Barad names as agential realism, in so far that agency is not something either the observer or the observed have as an intrinsic property, or prior to the experiment. For Barad, humans are part of the universe and entangled within the phenomenon of the world in its continuous reconfiguration. Thus, humans are part of knowledge production, but they do not have an exclusive birth right to knowing. In other words, humans do not mediate knowledge of the world through representation, but are a material part of knowledge production as a form of communication of the world between its parts. In this sense, that which is seen 
under observation as in classical physics, but neither is it a purely cultural or a social construction.

As an alternative to ontological separation and fragmented world-view, Bohm proposes a non-fragmented approach, which begins by acknowledging the ontological indivisibility of different parts as co-constitutive of reality. Fragment, Bohm argues, is instead seen as an independent whole. Fragmented world-view leads to more fragmentation and incoherence. Ontology of fragmentation is according to Bohm at the root of the many social problems and ecological crisis. In an interview that took place in the late eighties Bohm also makes reference how the understanding of independent nation-states reflects this fragmented world-view, which guides perception to find evidence of independence, instead of seeing how states are dependent on each other and organically entangled (also in Bohm 2005, p. 9) ${ }^{5}$. It is easy to see how the ontology of separation is at the core of international relations theory as the discipline begins with the frame of reference of independent sovereign states in anarchy ${ }^{6}$. Thus, things such as climate change or hurricanes, which do not respect state borders or international politics are seen as something which challenge international politics, whereas the trouble is rather the fragmented world-view which guides inquiry.

The non-fragmented approach which Bohm proposes is not intended as a new worldview or a paradigm, as this would entail another fragment. For Bohm, also theories and world-views should flow with the continuous movement of the reality. In this sense, when thought and non-thought are seen as connected and not ontologically separate, it follows that knowledge itself is understood as a process which emerges from or is part 
of the whole of movement of the universe. This movement should also apply to the worldviews by which we continue to make sense of the world we live in. Bohm writes (1996: p.89), "Rather, it can be said that our world views should 'flow with' the stream of reality as we come into ever-changing contact with the latter". Trying to fit the world into a fixed content of a worldview would ultimately not work, as it would mean trying to explain the continuous movement and continuous becoming with language which is already limited and reflects the fragmented world-view. It would mean imposing stability and fixedness on something which does not remain the same.

It is for this reason that I see the potential of posthumanist onto-epistemology as a way of resolving limited and human bound perceptions of the world, which focus on the problems and inequalities which humans inflict on the planet and on themselves. Posthumanist onto-epistemology would enable us to come in touch with how the thinking mind emerges in the process of the whole of the movement which we are already part of. This would also enable disattachment to our personal stories of ourselves and the way we see the world, recognize thinking as one manifestation of movement which we are part of. One aspect of this is to acknowledge how the physicalchemical-electrical properties of the brain give rise to consciousness, the sense of self, and sense of past, present and future (Hiley 2000). Thinking, can thus be also conceptualized as inner sensation of the body (Kabat-Zinn 2005, Brown et al 2007) or thoughts as secretions of the mind. In this way thinking is one aspect of our experience of being part of the world, instead of a source knowing the world as a separate reality. 
Bohm (1996, p. 88) explains the difference between the theory and worldview by showing that the word theory is derived from the Greek 'theoria'. This word has the same root as "theater," which in verb form means "to view." This means that we can regard theory as "a view" or a form of insight," rather than as a "well defined and certain knowledge about reality.' Using theory as a form of insight instead of representation of what is would enable also dialogue between different theories. If theory is a way of looking at the world, it cannot be either true of false, but a way of seeing which enables new insight. Bohm argues (2005) argues that one theory can only be clear up to a certain point until it tends to become unclear. Theories enable to have a clear view in one domain and not as clear in another. In this way, theories need not be in competition or evolve through falsification, but rather enable different perspectives. Theories evolve, Bohm argues, when we gain new facts, and in turn new facts shape theories. New theory enables new insight and opens new possibilities.

An interesting historical detail is that Newton was fascinated by clocks and collected them. The discovery of gravity and the understanding of causal laws were at the time new facts, which Newton wanted to fit into the clockwork model that so intrigued him (Bohm, 1996, Hakala 2002). Instead of seeing Newton's model as a form of insight into the world, which creatively combines his knowledge and love for the clockwork, it has turned into a world-view, which guides and limits perception of 'reality'. If, however, we were to approach Newtonian physics as a form of insight into the world, instead of a representation of the world, it would lose its power as true representation of the world. Yet, Newton's example tells us something very personal and intimate. It gives information on how our personal desires, likes and dislikes guide 
our perception and passion into what and how we study. It shows how intimately the observer and the observed co-constitute each other. Dare I even ask, how many IR theorists seek to fit the complex relations of the world into a preconceived model that they personally prefer and then convey these as the truth of the outside world? Yet, our personal preferences, belief systems and personal histories are erased from the view. Feminist methodology emphasizes self-reflectivity in terms of social situatedness, position of privilege and the authority of the author in representing social realities and in 'giving voice' to the disadvantaged and marginalized. Self-reflectivity means acknowledging the access to resources and the possibilities for mobility which are ineagually shared in the word. However, even these approaches do not go far enough to recognize how our thinking is an embodied and embedded process with the world. Next, I will turn to Barad's agential realism as a way to move beyond the mind body dualism and the prioritization of thinking minds in producing and mediating information.

As already mentioned, Barad argues for understanding of knowing and being in post-humanist terms, as communication between the parts of the universe, which need not be human. For Barad, the key is to theorize the meaning of the measurement problem, and the collapse of the wave-function with respect to subjectivity and agency which have been understood in humanist terms. To understand subjectivity as not necessarily human, never separate and never prior to the enfoldment of the phenomenon is a fundamentally different way of conceptualizing knowing and being from that familiar to social sciences. Consequently the human being is not defined as either a privileged knowing subject of enlightenment or in anti-humanist terms as a product of the social structure, or knowledge/power performativity, but as an agential realist (in 
terms of physical/material) entity active in the process of the (unpredictable and uncontrollable) becoming of the world. Zeilinger (1996) puts it as follows 'Finally, since we are part of the universe, the universe [], creates itself by observing itself through us.' Barad emphasizes that these agentially separated parts constitute the whole of the phenomenon, which is observed from the inside. There is no outside to the phenomenon.

Barad proposes an understanding of existence that does not take place in the world, but rather emerges from the process of continuous becoming. In this way, Barad's conceptualization of space-time is similar to Bohm's understanding of it as a projection and not a pre-existing place. Being, for Barad, is not a matter of being situated in terms of "occupying particular coordinates in space time and culture history" but is a rather "an iterative becoming of spacetimemattering" (Barad, 2007, p.234). For Barad, past and future does not operate like a continuum or container in which life happens, but both spacetime is also active and dynamic in the process of the continuous reconfiguration of the world. There is a sense of aliveness of the intra-actions in the process of spacetimemattering, and it is not a new form of vitalism, or soul substance, but "a new sense of aliveness" This understanding enables a view of the world as evercreative, and never contained. According to Barad (2007: 235) "Agency never ends; it can never "run out." This, assertion calls for recognizing the ongoing aliveness in the continuous movement and flow of the reality.

Barad (2007, p. 235) explains that "agency is a matter of intra-acting" and as such a matter of 'doing/being' and 'not something that someone or something has' 
What is crucial here is to rethink the idea of human dominance with respect to the natural world. Yet, Barad does not mean that agency is now also granted to non-humans (by humans), or divided between humans and non-humans. In other words, it is not a matter of extending or reconfiguring the domain of subjectivity and agency to include non-human species, or the environment. ${ }^{7}$ Agency has to be understood as agentiality superseding metaphysical individualism and hierarchical structure.

Questioning the limits of ontological assumptions behind the mechanistic worldview and opening a way of seeing physical world and space time as dynamic projections of enfolded order or process of spacetimemattering, does not necessarily mean a return to the understanding that there is an external soul substance, spirit or God moving the physical universe (Bohm, 1996). Rather, it points toward questioning the shared metaphysical individualism, ontological dualism between mind and matter, the observer and the observed which both objectivist and anti-foundational approaches share as long as intelligibility is conceptualized in humanist terms. Knowing in these approaches therefore involves mediation between inside and outside, humans as subjects in or outside the worlds they are studying. Barad highlights the problematics of understanding knowing as representation of the world. There is always a gap between the knowing subject and the world. How to overcome and close that gap turns into a debate on the correct lenses (feminist, post-colonialist, technological, economic, labor) with which to view the world. No matter what the lenses are, the common assumption is that knowing is a human-centered activity and the world surrenders itself to the human knowing subject. A non-fragmented approach would enable to move one step further 
and acknowledge intelligibility itself as a material process which emerges in the process of spacetimemattering which enables for us to experience the thinking mind.

In this section I have discussed the non-dualist onto-epistemology which Bohm and Barad respectively have developed based on the philosophical implication of quantum theory. At the heart of these ideas is the recognition of the inability of the Newtonian world-view to account for the non-locality and indeterminacy in space-time central to quantum mechanics. The evidence of quantum mechanics challenge our common sense dualist assumptions about ontology of separation between subjectobject, nature-culture, mind-body, self and other and so on. Bohm emphasizes that the enfolded order from which thinking and matter originate is bound for harmony and coherence. Fragmented world-view, is the result of human thinking, which leads to more incoherence and more fragments. Agential realist framework which Barad builds on Bohrs' philosophy-physics, brings even more emphasis on the role of the humans in the process of spacetimemattering. As there is no outside to the phenomenon, humans cannot afford the illusion of being outside or uninvolved with this process. As we are already and always part of the world, what we do also as IR scholars come to matter in fundamental ways.

I have argued elsewhere (Penttinen 2013) that how we perceive the world, what we deem as important and how we write has concrete material consequences. The world-view depicted by IR influences world-politics and vice versa. Therefore, what we choose to do, and how we choose to depict the world is not only an intellectual exercise 
within a separate world of academia. In the last section, I focus on how posthumanist onto-epistemology can enhance the practices of knowledge production in the field of IR.

CONCLUDING WORDS: TOWARDS A NEW ONTOLOGY OF ALIVENCESS OF MATTER

The opening quote by Schrödinger states "The world is given to me only once, not one existing and one perceived" challenges us to rethink the role of the observer in the process of knowledge production. If, as Schrödinger suggests there is no separation between subject and object also we as IR scholars, must rethink how we intra-act with the world and how these intra-actions generate material consequences within the world we are part of.

Finally, I want come back to the question of how posthumanist ontoepistemology of non-fragmentation can enhance the practice of IR scholarship. I propose a practice which begins with the posthumanist understanding of knowing as matter intra-active communication and inter-being. Coole and Frost (2010) emphasize that we must pay heed to recent developments in science which point towards aliveness and pluripotency of matter. Similarly, I want to argue that we have to be open to recognize how mind-matter relationships is reconfigured in the recent research of the neuroplasticity of the brain. This is a posthumanist conceptualization of knowing, which removes humans from the pedestal of knowing subjects and acknowledges material, chemical, electrical and as the very processes which give us a sense of who we are (i.e. the feeling of a separate thinking subject). Research on neuroplasticity of the brain and 
scientific study of mindfulness shows how thinking itself shapes the structure of the brain and can even increase the mass of the gray matter of the brain (Hölzel et al. 2011). This research shows that there is more to mind-matter relationship than is allowed in mechanistic world-view which sees matter as passive and without consciousness. Posthumanist onto-epistemology instead recognizes knowing as the inherent aliveness of spacetimemattering or the ongoing process of projections which emerge from the unified field beyond space-time.

This relates to the practice of IR in the sense that what we see that is true or relevant about the world is in relation to the world-view we practice. We are very good at practicing fear, and the beliefs in ontological scarcity and lack. I appreciate how Bousquet (2015) challenges us to think about the age of the Anthropocene in the context of longer view of the evolution of life on the planet earth. Human intelligence, the thinking mind, has enabled for the humans to dominate on the planet earth in relatively short period of time, only to bring the human species on the verge of destruction. However, much of the crisis on the planet earth is due to human thinking of the world in fragmented terms. In this way thinking matters in concrete terms. But would the destruction of the human race result in the destruction of all of life all intelligibility on this planet? To think in these terms would be narcissistic indeed. What results in the crisis on this planet is the incoherence in human thinking, i.e. the delusion of separation. Bohm emphasizes that 'nature' responds with incoherence to the incoherence in human thinking. Barad proposes an ethics of diffraction to account for the responsibility of humans as part of the intra-active process of becoming. 
I see International Relations as a discipline that could be the place for imagining more sustainable systems of thinking, governance and indeed human to human and nonhuman relations. In this field we are in the business of thinking globally irrespective of what we choose to focus on. What makes IR so challenging and intriguing as field of inquiry is exactly the challenge to contextualize local or distinct events in the context of global politics and processes. Therefore, I see the potential in continuing even further by adopting a non-fragmented, non-dualist onto-epistemology which recognizes how we are already part of the ongoing configuration of the world, not as individual subjects observing the world from a specific point in time, but as intra-active parts participating in the world in its continuous becoming.

Posthumanist onto-epistemology calls for re-evaluation of the position of the researcher inquiring into, theorizing and mediating the world of (international) relations. If the human observer is already entangled within the phenomenon through which nature-culture is reconfigured, this will entail a new level of accountability and responsibility in the way we practice knowledge production. Recognizing thinking and knowing as projection of the enfolded order and as always already in intra-active relation to the other bodies and projections is first and foremost an ethical question. Barad names this as ethics of diffraction which is based on quantum optics instead of physical optics. What and how we affect the world cannot be reduced linear lines or push and pull factors. Instead our thoughts and actions reverberate like waves, crossing other waves and creating new forms and formations. 
Letting go of mechanistic-deterministic (materialist) world-view mean a return to myth, or conceptualization of the divine as an external soul substance moving the world. This is not what the enfolded order beyond space and time refers to. It means rather acknowledging ourselves as intra-active parts in the whole of movement and not separate thinking subjects viewing the world from nowhere or from a particular social/cultural somewhere. In this framework the grand-narratives of survival of the fittest and competition and lack of resources are seen as human made constructs, or rather, representation of incoherence in human thinking. Even if Newtonian world-view has been challenged and contested in terms of how it would applies to the social world (see e.g. Grosz, 1994), still the ontology of separation functions almost like a ghost, or an unquestioned belief, stimulating us to ask questions and inquire about the social world in a problem/struggle-oriented form, tying us to lack and hierarchical dualisms as true representations of the world.

The non-fragmented worldview means a fundamentally new onto-epistemology. It leads to recognition of the aliveness of matter and recognition of relationality knowing and being as part of the world. The new ontology of aliveness of matter and post-humanist understanding of subjectivity and agency will lead us toward recognizing the pluripotency and continuous emergence of life, recognizing the vitality of intraactions, including our own. Thus, at the heart of the Barad's and Bohm's posthumanist onto-epistemology is the awakening to our responsibility as we are already entangled with the whole of the phenomenon of the world in its continuous reconfiguration. Perhaps as IR scholars, we could be the forerunners in inspiring new coherent ways of intra-acting with the world on a global scale in order to ensure the survival of the human species on this precious planet earth that gives us life. 
${ }^{1}$ Particle physicist Erwin Schrödinger quotes http://www.brainyquote.com/quotes/authors/e/erwin schrodinger.html, accessed 22nd November 2011.

${ }^{2}$. http://www.forbes.com/sites/alexknapp/2012/05/11/chinese-researchers-quantumteleport-photons-over-60-miles/

${ }^{3}$ This was the stance adopted by Einstein (Barad, 2007)

${ }^{4}$ Phillip F. Schewe and Ben Stein, Physics News Update 453, Indie Science research, American Institute of Physics, Number 453, October 19, 1999 by http://www.aip.org/pnu/1999/physnews.453.htm\#2, accessed November 2011. ${ }_{5}^{5}$ Interview with David Bohm at the Niels Bohr institute in Copenhagen in 1989 https://www.youtube.com/watch? $\mathrm{v}=\mathrm{QI} 66 \mathrm{ZglzcO} 0$ accessed $25^{\text {th }}$ of November 2015. ${ }^{6}$ One could also ask, what kind of cognitive repression is taking place in IR scholarship as still the textbooks created for students build a story of IR through the state-centric theory and tensions between realism and liberalism. Only few examples suchs as Weber (2009) turn also the introductory texts around. In practice the old fashioned, perhaps even retro textbooks easily create odd experiences in the classroom, where young students defend the IR past as an appropriate approach to studying international relations in the contemporary world.

${ }^{7}$ The domain of subjectivity is a concept which refers to a recognized social subject, which is constructed through differentiation from social others, such as homosexuals, or exotic others (Butler 1997).

References:

Ahmed, S 2006, Queer Phenomenology: Orientations, Objects, Others. Duke

University Press, Durham.

Barad, K 2003, Posthumanist Performativity: Toward an Understanding of How Matter Comes to Matter, Signs, vol. 28, no. 3.pp. 801-31.

Barad, K 2007, Meeting the Universe halfway: Quantum Physics and the Entanglement of Matter and Meaning,,Duke University Press, Durham. 
Barkawi T, B Shane (2011) Powers of War: Fighting, Knowledge and Critique, in International Political Sociology, 5 (2), pp.126-143.

Bennett, J 2010, Vibrant Matter: a Political Ecology of Things, Duke University Press, Durham.

Bohm, D 1996, On Creativity, Routledge, London.

Bohm, D 2007, On Dialogue, Routledge, London

Bohm, D 2005, Implicate Order, Routledge, London.

Bousquet, A 2015, 'Prolegomena to Post-Anthropocentric International Relations: Biosphere and Technosphere in the Age of Global Complexity' in E Kavalski (ed.), World Politics at the Edge of Chaos: Reflections on Complexity and Global Life, SUNY Press Albany, NY.

Braidotti, R 2006, Transpositions, Polity Press, Cambridge.

Brown, K W, R M. Ryan, J. D Creswell 2007, ‘Addressing Fundamental Questions About Mindfulness', Psychological Inquiry, 18 (4)pp. 272-281.

Butler, J 1997, The Psychic Life of Power: Theories in Subjection, Standford University Press, Standford California.

Chan S 2011, 'On the uselessness of the new wars theory: lessons from African conflicts', in C Sylvester (ed) Experiencing War, Routledge, London.

Coole, D H, S Frost 2010, 'Introducing New Materialism, in D H. Coole, S Frost (eds) New Materialisms: Ontology, Agency and Politics, Durham: Duke University Press. 
Cudworth E. and Hobden S. 2011, Posthuman International Relations: Complexity, Ecologism and Global Politics, Zed Books, London.

Churchland P 2012, Braintrust: What Neuroscience Tells Us about Morality, Princeton University Press, Princeton.

Csikszentmihalyi, M 2011, 'Positive Psychology and Positive World-view: New Hope for the Future of Humankind', in S I Donaldson, M Csikszentmihalyi, J Nakamura (eds) Applied positive psychology: improving everyday life, health, schools, work and society, New York: Psychology Press.

Damasio 1999 The feeling of what happens: body and emotion in the making of consciousness, Harcourt Inc, Orlando.

Der Derian J 2009, Virtuous War: Mapping the Military-Industrial-MediaEntertainment-Network, Routledge: London.

Der Derian J 2013, 'From War 2.0 to quantum war: the superpositionality of global violence', Australian Journal of International Affairs, 67 (5) pp. 570-585

Ferrando, F 2015, ‘A Spiritual Genealogy of the Posthuman', in D Banerji, ed.Critical Posthumanism, Planetary Futures, Springer India.

Grosz, E. 1994: Volatile Bodies: towards corporeal feminism, Bloomington: University of Indiana Press.

Hakala, J. T. 2002, Luova prosessi tieteessä. Gaudeamus, Helsinki

Hameroff, S R 2007, 'The Brain Is Both Neurocomputer and Quantum Computer', Cognitive Science, 31,pp. 1035-1045.

Hari 2015, 'Magnetoencephalography studies of action observation' in Pier F Ferrari, Giacomo Rizzolatti (eds) New Frontiers in Mirror Neurons Research. Oxford University Press.Oxford pp 58-70. 
Hiley, B.J. 2000, 'Non-commutative Geometry, the Bohm Interpretation and the MindMatter Relationship' To appear in Proc. CASYS'2000, Liege, Belgium, Aug. 7-12, 2000 .

Hölzel B K., J Carmody, M Vangel, C Congleton, S M. Yerramsetti, T Gard, S W. Lazar 2011, 'Mindfulness practice leads to increases in regional brain gray matter density', Psychiatry Research: Neuroimagining, 191 (2011) 36-43.

Isen A M 2009, 'A Role of Neuropsychology in Understanding the Facilitating Influence of Positive Affect on Social Behaviour and Cognitive Processes', in C.R. Snyder and Shane J. Lopez (eds) Oxford Handbook of Positive Psychology, New York: Oxford University Press.

Kabat-Zinn, J 2003, 'Mindfulness-Based Interventions in Context: Past, Present and Future', Clinical Psychology: Science and Practice, 10 (2). pp.144-156.

Kaku, M 2000, Strings, Conformal fields and M-theory: an introduction (Graduate texts in contemporary physics). Springer-Verlag, New York.

Kallio-Tamminen T 2008, Kvanttilainen todellisuus: Fysiikka ja filosofia maailmankuvan muovaajina, Gaudeamus Helsinki University Press,Helsinki.

Kwee, M.G.T. 2012, ‘Relational Buddhism: Wedding K.J. Gergen’s Relational Being and Buddhism to Create Harmony In-Between-Selves'. Psychological Studies, 57 (2), pp. 203-10.

Penttinen E. 2013, Joy and International Relations: a new methodology. Routledge, London.

Rosenblum, B. and Fred Kuttner 2006, Quantum Enigma: Physics Encounters Consciousness, Oxford University Press, Oxford. 
Stengers, Isabelle 2010, Cosmpolitics I (Posthumanities), translated into English by Robert Bononno, University of Minnesota Press, Minnesota.

Sylvester, C. 2009, Art/Museums: International Relations Where We Least Expect It, Paradigm Press, Washington.

Walker, R. B. J. 2010, After the Globe, Before the World, Routledge, London.

Weber, C. 2009, International Relations Theory: a Critical Introduction, Third Edition, Routledge, London.

Zeilinger, A. 1996, On the Interpretation and Philosophical Foundation of Quantum Mechanics in U. Ketvel et al. (eds.) "Vastakohtien todellisuus", Festschrift for K.V. Laurikainen, Helsinki: Helsinki University Press. 